\title{
Lessons about work readiness from final year paramedic students in an Australian university
}

\author{
Kylie O'Brien $\mathrm{PhD}^{1,2}$, Amber Moore BChinMed(Hons) ${ }^{2,3}$, Peter Hartley $\mathrm{PhD}^{2}$, David Dawson MBA ${ }^{2}$ \\ Affiliations: \\ ${ }^{1}$ Deakin University, Burwood, Victoria, Australia \\ ${ }^{2}$ Victoria University, Melbourne, Australia \\ ${ }^{3}$ Dept. of Medicine, Monash University, Melbourne, Australia
}

\begin{abstract}
Background

Paramedic education is changing in Australia from a post-employment model in which in-house training is provided by state-based service providers to pre-employment Bachelor degree education in universities. Little is known about how well prepared final year paramedic students nearing the end of their university course perceive themselves to be to enter the workforce. The objective of the study was to investigate perceptions of preparedness for the workforce of final year paramedic students at Victoria University, Melbourne, Australia.
\end{abstract}

\section{Methods}

A survey was conducted with final year paramedic students in their last semester at Victoria University, Melbourne, Australia. The survey focussed on eight dimensions relating to paramedic practice: theoretical skills, clinical skills; practical skills; interpersonal skills; communication with colleagues and other professionals; coping skills; lifelong learning; and ethics and legal responsibilities. Part 1 of the survey required participants to choose from six possible responses on how well they believe their paramedic course has prepared them in relation to 64 statements. Part 2 consisted of 5 open- ended questions. Data from part 1 was analysed to find the mean 'preparedness scores' on the 8 dimensions of paramedic practice. Responses from part 2 of survey were transcribed and imported into NVivo8, where each part of the questions were analysed and grouped into themes.

\section{Results}

Response rate was $14 \%(n=23)$. Respondents felt 'somewhat adequately' to 'adequately' prepared for the workforce. Responses to Part 2 indicated a range of perceptions in relation to preparedness to enter the paramedic workforce, ranging from feeling unprepared to put knowledge into practice, prepared in some aspects but not in others, through to feeling prepared but with a realisation that there would be much to learn on the job. Respondents comments provide paramedic educators with some clear ideas about what final year students value in terms of preparing them for practice: whilst respondents valued the clinical practice opportunities they had had, they wanted more clinical placements with more variety, for example placements in different areas of healthcare.

\section{Conclusion}

This small survey provides paramedic educators with some clear ideas about what final year students value in terms of preparing them for practice. As Australian paramedic education moves from a post-employment training model to a pre-employment model, further consideration is needed of how courses will best address the development of clinical and practical skills of students and meet the requirements of ambulance service employers. Collegiate dialogue between employers, educators and students will assist in addressing this.

\section{Keywords}

work readiness, education, paramedics, problem based learning, work integrated learning, curriculum 


\section{INTRODUCTION}

The role of the paramedic has changed significantly from simply a transporter of persons to hospital to now include the assessment, treatment and referral or transport of the patient to an appropriate care facility.(1) In more recent times the scope of practice has expanded to include provision of more complex and invasive techniques with the advancement of medical technology, and greater critical thinking and clinical decision making that permits paramedics to make informed judgments about whether to transport a patient for definitive care or leave the patient at home with appropriate referrals. In some Australian states, particularly in rural communities, consideration has been given to the expansion of the scope of paramedic practice to include roles and functions that are non-traditional paramedic care and that would normally be carried out by other health practitioners, as a result of health workforce shortages. (2) These include minor surgery, investigative procedures such as endoscopies, anaesthetics and to be able to request some diagnostic tests.(2)

Likewise, education of paramedics in Australia has undergone significant changes over the past 50 years. A progression has occurred, from minimal educational requirements (such as only needing first aid training), to exclusively in-house post-employment training provided by state-based service providers (such as Ambulance Victoria in the state of Victoria) to the present mix of postemployment courses and pre-employment University Bachelor degree courses.(3) The profession is still in a transition phase with respect to education. Victoria is the only state with mandatory education requirements of a Bachelor of Health Science (Paramedics) for employment with Ambulance Victoria. South Australia and Western Australia have also discontinued all inhouse paramedic courses and have moved to higher education courses.(1) The other states and territories still have a mixture of post-employment and pre-employment training models. However, all Australian states and territories will move to university-based (pre-employment model) by 2015.(4)

Currently twelve universities in Australia (plus two in New Zealand) offer paramedic courses at Bachelor degree level. Some universities also offer postgraduate courses.(5) However, currently there are no officially adopted national competencies for Bachelor degree level paramedic courses (only a set of national diploma level competencies), or national practice standards.(6) This has been flagged as an important issue for the paramedic profession by Williams and colleagues who warn that this leads to inconsistency in paramedic curricula, something compounded by the fact that ambulance services within Australia work independently of each other and in many cases, universities. (6) National competencies have been developed by two different authorities, one by the Council of Ambulance Authorities and another by Paramedics Australasia. In the absence of statutory regulation the national competencies exist to underpin HE course accreditation processes.

Relatively little is known, other than anecdotally, about how well prepared paramedics from preemployment University courses are to enter the workforce, with only a few published studies in the paramedic field. In Dawson's study of Victoria University (VU) paramedic students, several themes emerged with respect to job readiness.(3) The main themes to emerge from the student interviews in Dawson's study were that students felt the paramedic course provided them with a good theoretical background however they felt underprepared in terms of the practical experience in working with the ambulance service and needed hospital placements to gain necessary experience and understanding of the hospital environment.(3) Interviews with supervisors of students in the course suggest that practical skills of students schooled in the VU course improve over time and are the same as students trained in the old 'on the job' training course.(3) Waxman and William's survey of Monash University pre-employment students' concerns about gaining employment with ambulance services in Australia found that twothirds of final year students felt ill prepared for the employment application and selection process. (7) The transition from the final year of a university (or other) course into the workforce is a particularly critical time for new graduates, particularly those with limited previous work experience, consistent with findings of Dawson's study.(3) It has been estimated that in the United States of America, 'approximately 50 to 80 percent of new college graduates leave their first job within the first three years'.(8) Hettich describes several dimensions that may contribute to this: the difference in corporate culture compared with college culture, cognitive development, 'successful' and 'emotional' intelligence and competencies, workplace preparedness, psychosocial development, learning and motivational issues, interpersonal and group skills, career planning and skills for independent living8. There are several studies that investigate preparedness 
within other disciplines, including medicine (9-11), dentistry (12), nursing (13), nurse practitioners (14), Chinese medicine (15), physiotherapy (16), and occupational therapy (17). There are no published studies that specifically investigate the perceptions of paramedic students about to graduate on work-readiness.

VU delivers a three-year, full-time preemployment Bachelor degree course in paramedics that has been conducted in its current form since 2006, though earlier iterations of the curriculum have been taught at VU since 1999.(3) The VU course has a very 'hands-on' focus. It incorporates development of critical thinking and analysis as would be expected of a higher education course, and maintains a strong emphasis on clinical skill development. Simulation activities, practical laboratories with state-of-theart equipment, and clinical placements in a variety of settings feature strongly in the course. Students commence clinical placements in semester 1 of year 1 , ensuring that they are exposed of all facets of pre-hospital care, including emergency and non- emergency situations. In view of the fact that there is little information in the literature about how well prepared for the workforce paramedic students feel, and as part of a quality assurance practice, we decided to conduct a survey of final year paramedic students at VU. The objectives of the study were to investigate the perceptions of readiness for the workforce in final year paramedic at Victoria University, to understand in particular the strengths of the VU paramedic course and how it could be improved so that the transition into the workplace is facilitated.

\section{METHODS}

\section{Survey Instrument}

The survey was developed in two parts. Part 1 of the survey was based on an approach taken by Hill and colleagues (18) in the design of a survey to measure preparedness for clinical practice of western medical practitioner interns. Part 1 of our survey consisted of 64 statements about paramedic practice, subdivided into eight areas or dimensions relating to paramedic practice. In the absence of national graduate capabilities for paramedic students, the dimensions of paramedic practice and 64 statements were developed in consultation with five paramedic academics and educators in Australia, in order to ensure content validity.

Participants were required to choose from six possible responses in relation to how well their degree had prepared them with respect to each specific topic: very inadequately [1]; inadequately [2]; somewhat inadequately [3]; somewhat adequately [4]; adequately [5]; and very adequately [6]. The eight dimensions are set out below, along with the statements relating to them. The 64 statements are included in Appendix 1.

- Dimension 1: Theoretical knowledge

(Statements 1, 18, 24, 29, 49, 61)

- Dimension 2: Clinical skills (Statements 2, 8, $9,10,21,22,27,30,39,41,44,47,48,50$, 53)

- Dimension 3: Practical skills (Statements 4, 16, 19, 23, 28, 43, 46)

- Dimension 4: Interpersonal skills (Statements $3,17,32,34,38,42,45,51,54,60,62)$

- Dimension 5: Communication with colleagues and other professionals (Statements 5, 13, 15, 20, 26, 40, 58, 59)

- Dimension 6: Coping skills (Statements 6, 11, 14, 33, 36, 55, 64)

- Dimension 7: Lifelong learning (Statements 7, $12,25,35,56,63)$

- Dimension 8: Ethics and legal responsibilities (Statements 31, 37, 52, 57)

A distinction was made between those skills directly associated with medical care of the patient, termed 'clinical skills' (such as taking a case history, applying basic life support techniques) and 'practical skills' which were associated with indirectly associated with the clinical care of a patient (such as driving an ambulance, maintaining equipment, loading and unloading a stretcher). Part 2 of the survey consisted of five open- ended questions relating to the transition from student to paramedic practitioner and critique of the paramedic course.

\section{Data Analysis}

\section{Part 1}

Internal consistency or reliability of items within each of the eight dimensions was analysed by calculating the Cronbach alpha coefficient. Systematic deletion of items and recalculation of alpha coefficients was conducted to maximise reliability. It is generally accepted that if the alpha coefficient is greater than 0.7 , there is an acceptable level of internal consistency.(19) The quantitative data was analysed using the statistics package SPSS 15.0 for Windows. Mean preparedness scores and their standard deviations were calculated for each of the eight dimensions.

\section{Part 2}

A similar method of analysis of data was used in this study as was employed in Moore and colleagues' study of preparedness for clinical practice in Chinese medicine students.(15) We 
analysed the qualitative data with the assistance of the qualitative software NVivo.(8) The transcribed responses to the open-ended questions were imported into NVivo with the independent variables or 'attributes' of each respondent preserved as 'cases' linked to each survey.(8) The preservation of attributes enabled greater depth and breadth of analysis. The use of this software facilitated a level of quantitative analysis of the responses arising from the openended questions. Some questions or parts of questions yielded easily quantifiable responses with one response per respondent, other questions yielded multi-themed responses where the sum of responses for that question is greater than $100 \%$. Each part of the questions were analysed and grouped into themes.

\section{RESULTS}

A total of 23 out of 171 final year paramedic students replied to the survey which was conducted in the final weeks of Semester 2, 2010, giving a response rate of $14 \%$.

Baseline demographic data of respondents, including previous qualifications and previous work experience, is set out in Table 1. It is unknown if the demographic characteristics of responders was any different to non-responders. However, it is known that the majority of paramedic students at VU are not from nonEnglish speaking backgrounds. There were some respondents $(n=7)$ who, in their final year of the paramedics course were employed with the state ambulance authority because of a shortage of paramedics. These students completed the final year of their course on-line (instead of oncampus), concurrent with being employed.

The Cronbach alpha coefficients for all dimensions were 0.7 or above. Mean preparedness scores for the nine dimensions of engineering practice are set out in Table 2. A copy of the survey may be found in Appendix 1.

\begin{tabular}{|c|c|c|}
\hline Criteria & \multicolumn{2}{|c|}{ Overall } \\
\hline No. of respondents & \multicolumn{2}{|l|}{23} \\
\hline Age (years, SD) & \multicolumn{2}{|c|}{$27 \pm 5.8(n=23)$} \\
\hline Gender & \multicolumn{2}{|c|}{$\begin{array}{l}\text { Male: } n=12 \\
\text { Female: } n=10 \\
\text { Missing: } n=1\end{array}$} \\
\hline Previous qualification & \multicolumn{2}{|c|}{$\begin{array}{l}\text { No: } n=9(39 \%) \\
\text { Degree, diploma or } \\
\text { certificate: } n=7(30 \%) \\
\text { Other employment: } n=3 \\
\text { Workplace first aid } \\
\text { officer: } n=2 \\
\text { No response: } n=2\end{array}$} \\
\hline $\begin{array}{l}\text { Aboriginal or Torres } \\
\text { Strait Islander }\end{array}$ & \multicolumn{2}{|c|}{$\begin{array}{l}\text { Yes: } n=0 \\
\text { No: } n=23(100 \%)\end{array}$} \\
\hline International Student & \multicolumn{2}{|c|}{$\begin{array}{l}\text { Yes: } n=0 \\
\text { No: } n=23(100 \%)\end{array}$} \\
\hline $\begin{array}{l}\text { Currently employed as a } \\
\text { paramedic }(n=18)\end{array}$ & \multicolumn{2}{|c|}{$\begin{array}{l}\text { Yes: } n=7(30 \%) \\
\text { No: } n=11(48 \%) \\
\text { No response: } n=5\end{array}$} \\
\hline $\begin{array}{l}\text { If employed as a } \\
\text { paramedic, for how long? }\end{array}$ & \multicolumn{2}{|c|}{$\begin{array}{l}16-18 \text { months: } n=4 \\
12 \text { months: } n=1 \\
6 \text { months: } n=1 \\
1 \text { day: } n=1\end{array}$} \\
\hline Dimension & & $\begin{array}{c}\text { Mean } \\
\text { score* }^{*} \text { SD) }\end{array}$ \\
\hline 1. Theoretical knowledge & $(n=18)$ & $4.1 \pm 1.0$ \\
\hline 2. Clinical skills $(n=18)$ & & $5.1 \pm 0.8$ \\
\hline 3. Practical skills $(n=19)$ & & $5.1 \pm 0.7$ \\
\hline 4. Interpersonal skills $(n=1$ & 19) & $4.9 \pm 0.6$ \\
\hline $\begin{array}{l}\text { 5. Communication with co } \\
\text { other professionals }(n=18)\end{array}$ & $\begin{array}{l}\text { olleagues \& } \\
\text { ) }\end{array}$ & $4.6 \pm 0.8$ \\
\hline 6. Coping skills $(n=19)$ & & $4.6 \pm 0.8$ \\
\hline 7. Lifelong learning $(n=20)$ & & $4.7 \pm 0.7$ \\
\hline 8. Ethics \& legal responsil & ibilities $(n=19$ & $5.2 \pm 0.7$ \\
\hline
\end{tabular}

Table 2: Mean Preparedness Scores for the Nine Dimensions of Paramedic Practice

*Preparedness rated on a scale of 1-6 where $1=$ very inadequately, $2=$ inadequately, $3=$ somewhat inadequately, $4=$ somewhat adequately, $5=$ adequately, $6=$ very adequately

\section{Part 2}

Table 3 sets out the major responses elicited from the long answer questions. 


\section{Part 2: Question Responses (and codes)}

Do you consider that Somewhat prepared $=3(1$ you were, or will be, employed) prepared for the $\quad$ No $=6$ ( 3 employed) transition into the $\quad$ Yes $=9(3$ employed $)$ paramedic workforce at the end of your course?

Course improvements needed $=3$ ( 2 employed)
Self-learning required $=3(1$ employed)

Unsure of roles and expectations $=2(2$ employed)

Previous work experience helped $=1$ (employed)

Received help from instructors $=1$ (employed)

In terms of preparing Clinical practice and you for work as a placement $=14$ paramedic, what were Anatomy and the best aspects of pathophysiology $=6$ your course?

Pharmacology $=4$
Lecturers $=2$

Clinical Practice Guidelines $=2$

Scenarios $=2$

Advanced paramedic practice $=2$

In terms of preparing More clinical training $=10$ you for work as a Placements in different paramedic, what were areas of hospital and aspects of your healthcare $=5$ paramedic course More real-life scenarios $=4$ could be improved? More practical pharmacology including drug calculations $=4$ Lecturers $=2$ Less practitioner health subjects $=2$

More equipment familiarisation $=2$ Driving training $=2$ Mental health subject relevant to paramedicine $=2$ More CPG's = 2

Maths $=1$

Subjects tailored more to paramedics $=1$
How useful were the Very useful $=9$

ambulance service Extremely useful $=3$

placements during Useful $=2$

your course in

preparing you for

entering the

ambulance

workforce?

Want more $=7$

Helped understand the job $=$ 5

Saw how to communicate

with patients $=2$

Learnt a lot $=1$

Gained confidence $=1$

Table 3: Analysis of Part 2 responses

\section{Preparedness for transition into the paramedic workforce}

As set out in Table 3, approximately $66 \%$ of those who responded indicated they will be prepared for transition into the workforce at the end of their course. The following individual responses further highlight the perspectives more frequently mentioned by the students surveyed. For example, some students indicated an appreciation of the fact that learning is a continuum and that it will consolidate and continue on the job. One student (ID 6) commented:

"I think I will be prepared but I think once I get into the workforce there will be a lot to learn on the job".

Another (ID 23) commented:

"Somewhat. I think the course has given me a lot of information which l'll need to review and consolidate when I start work".

Another quote (ID 9) was:

"In certain aspects yes. In others not quite, but that is mainly due to lack of experience and exposure".

Two respondents who had begun work reflect similarly in relation to preparedness. Both indicate not feeling prepared, and articulate the value of learning on the job once they began work. One respondent (ID 14, employed) said:

"I feel as though I was not prepared. The answers I have given previously state how I was feeling in my first month on the road. I now feel as though I have learnt a lot and got motivation for self learning whilst at work. I now feel very confident with everything because I had help from others (clinical instructors) going over things with me and teaching me things I had either forgotten or did not learn enough of". 
Another student (ID 8, employed) who felt unprepared stated:

$$
\begin{aligned}
& \text { "....My first few months on road were quite } \\
& \text { difficult and I had to work hard to develop } \\
& \text { my skills and how to apply the CPG's to } \\
& \text { patients. As I tell a lot of new people } \\
& \text { coming into the job now, it is one thing to } \\
& \text { know the CPG's, it is another to apply } \\
& \text { them..." }
\end{aligned}
$$

Results suggest that while a majority of students felt prepared to enter the workforce, they recognised the value of experience and that there would be much to learn once they began working. Education

The most popular aspects of the paramedic course related to clinical practice and placements. One of the features of the VU course is the strong clinical practical focus. The responses indicated the value students give to placements, a sentiment that was often repeated.

\section{Best aspects of the course}

In response to the question of what were the best aspects of the course in preparing (you) for work as a paramedic, one student (ID 5) commented:

"Clinical practice sessions, however there needs to be more hours per week and a greater focus on pharmacological and pathophysiological reasoning for treatment."

Another respondent (ID 16) stated:

"Practical is always helpful, especially in 2nd/year first semester when it ran with the pathophysiology course. Pathophysiology ran a week before the practical class, so we actually had an idea how things worked. 2nd semester however it seemed to be the opposite way around. Anatomy, pathophysiology and pharmacology are very beneficial. Advanced paramedic practice was good as we learnt more advanced skills and hospital treatment, giving us knowledge of what the patient might require at hospital".

These comments illustrate the value of alignment of theoretical subjects with practical training.

One student (ID 4, employed) commented:

"Best aspects was the encouragement to critically think. Learn and understand the CPGs (Clinical Practice Guidelines)".

\section{Placements}

When asked how useful the ambulance service placements were during the course in preparing the student for entering the ambulance workforce, 14 respondents $(61 \%)$ found these useful or very useful. Five respondents indicated that in particular it helped them understand the role of the paramedic, what the job was about. For example, one respondent (ID 14, employed) said: 'It gave me a feel of the types of jobs paramedics mostly go to. It also gave use an opportunity to listen to how paramedics communicate with patients".

Another (ID 22) commented:

"Very useful - great way to really SEE what working as a paramedic will be like".

Several students wanted more and/or longer clinical placements. One detailed response (ID 2) was the following:
"Good and bad. They were excellent because as a student, I was able to see what really went on. When placed with a good crew, I was also able to practice some of the skills I had learnt....... Longer groups of placements would have been more beneficial as a better rapport would be gained with the paramedics. Also, paramedics and students alike seem quite unclear as to what an observer is actually able to do...."

The following comment (ID 15) about rural placements is reflective of the nature of rural paramedic work where the number of call outs is typically significantly less than in metropolitan areas:

"Rural placements were ok but no many jobs and no experience achieved".

This following comment suggests an appreciation of the value of placements, yet also indicates some limitations of the experiences associated with placements for one respondent:
"Very useful to get a glimpse of how paramedics and AV work. In terms of clinical competency there was no opportunities in my placements to really test it'. (ID 23)

The reality of clinical placements is that there is variation in terms of range of clinical experiences and volume of contact with patients. This is not unique to paramedic courses and can occur in other clinical courses. For example, a nation-wide 
survey of Chinese medicine students preparedness for the workforce in Australia found that $35 \%$ of respondents nominated clinical aspects of the course as needing improvement, with criticisms including not enough clinical work and observation and numbers of students being too high in the student clinic (14).

\section{Course Improvements}

In terms of which aspects of the course could be improved, interestingly almost half of the respondents wanted more clinical training, and several suggested placements in different areas of hospital and healthcare. One comment (ID 16) was:

\section{"More placements, maybe including work in certain areas of a hospital, such as emergency department, maternity ward, etc. ......Need more information on what patient goes to what hospital. What equipment certain hospitals have....".}

A few students suggested a need for practical training and placements in mental health. Greater tailoring of units to paramedics, for example in units covering law and ethics, was another suggestion. One student (ID 9) felt that:

\section{"More placements, more time on anatomy and physiology, more practical pharmacology and mental health-more relevant and specific to paramedicine".}

Another (ID 10) said:
"I think making subjects more tailored to paramedics. For example law and ethics could just go over the law and ethics surrounding paramedics and our profession."

\section{DISCUSSION}

This was the first published survey to investigate how prepared final year paramedic students in an Australian pre-employment university degree course perceived themselves to be to enter the workforce, in relation to a range of capabilities and skills required of practising paramedics. Results of this survey suggest students perceive themselves to be 'somewhat prepared' or 'prepared' for entry into the workforce. This finding is similar to other studies that have investigated preparedness for practice in students and graduates of different healthcare disciplines including medicine (9-11), dentistry (12), nursing (13), nurse practitioners (14), Chinese medicine (15), physiotherapy (16), and occupational therapy (17), which found that overall students generally view themselves prepared for entry into the workplace. In contrast, as reported earlier, Waxman and William's survey of Monash University pre-employment students found that two-thirds of final year students felt ill prepared for the employment application and selection process.(7) Dawson's previous study in third year paramedic students some of whom were already employed, found that respondents were confident with respect to knowledge but lacked confidence in clinical and practical skills.(3)

This was a voluntary survey and as such, it is acknowledged that a potential limitation of the study may be related to self-selection bias. The response rate to the survey was low. The survey was conducted in the last few weeks of their degree, and the majority of students were offcampus on location at clinic placements at the time. While students are required to check their email weekly, this time of semester, while chosen purposefully to capture the students at the end of their studies, may have adversely affected the number of responses and therefore the generalizability of the quantitative findings. Future studies may benefit from adjusting the timing of the survey, or employing other methods of capture such as paper distribution, multiple response options, or expanding the survey to include multiple universities. Nonetheless, the sample size was adequate with respect to the qualitative analysis of the long answer questions that generated several themes. The value in the feedback for paramedic educators is in considering, in particular, the responses to the long-answer provided by respondents.

The results of Part 1 suggest that survey respondents feel 'somewhat adequately' to 'adequately' prepared with respect to nine key dimensions of paramedic practice. Results from the second part of the survey suggest that clinical practice and placements are very important to students, cited by the majority of respondents as one of the best aspects of the course in terms of preparing them for the workforce as paramedics. This was corroborated by responses to the last long answer question that asked 'How useful were the ambulance service placements during your course in preparing you for entering the ambulance workforce?'

A common theme that emerged with respect to how the course could be improved to prepare graduates to work as paramedics was again related to this topic: respondents suggested more clinical placements and in a greater variety of areas within hospitals and the healthcare system. This first suggestion is similar to the findings of several other disciplines, for example Chinese medicine (15), and nurse practitioners (14), where students expressed a desire for more rigorous and relevant clinical placement experiences. 
The issue of clinical placements in Australian paramedic courses has been raised in other studies in relation to amount of hours, effectiveness, experience and relationship to learning objectives.(5) As Hou and colleagues point out, more research is needed to establish an evidence base with respect to quantity and quality of clinical placements that can guide education.(5) Challenges to Paramedic Education in Australia This study, albeit limited, reports the findings from a small cohort of students of an HE paramedic course. The Council of Ambulance Authorities Inc. 2008 submission to the National Health and Hospitals Reform Commission stated that a significant issue facing Australian ambulance services was 'ensuring paramedics graduate from university as work ready paramedics with not only appropriate clinical ability but a multi skilled practitioner who is responsible for the out-ofhospital clinical care and safety of their patients and the community as a whole...'.(20) As the paramedic higher education system struggles to establish itself in the dominion of academia, coupled with the complexities and contrasts of its established roots in vocational education (VE), a major challenge emerging appears to be how 'work readiness' is defined, and expectations of the key stakeholders in terms of work readiness.

The move into the HE sector has seen the induction of the philosophies of HE into paramedic education courses. For example, graduate capabilities are now commonly found within university strategic plans and mission statements in the HE sector in Australia and internationallythese relate not only to discipline-specific capabilities (in paramedics, an example would be clinical diagnostic skills) but also include generic capabilities such as problem-solving, critical thinking, communication and life-long learning.(21) In the VU course, such generic skills, contextualised within the paramedic profession, are explicitly developed. Generic capabilities, the term often used interchangeably with 'employability skills', are expected components of 'work readiness' or 'career readiness' in graduates from the HE perspective. The Australian government's report Transforming Australia's Higher Education states that the purpose of higher education includes 'skills of critical analysis and independent thought to support full participation in a civil society' and 'the preparation of leaders for diverse, global environments'.(22) The industry focus, however, is still biased towards a definition of 'work readiness' that equates with practical competence, 'competency' being the province of VE courses.

The previous post-employment apprenticeship style model of education provided considerably more practical clinical exposure by design. In the experience of two of the co-authors who have been involved in paramedic education for over ten years, constraints around clinical placement availability, coupled with the shift in focus from VE/Further Education to HE pedagogy has resulted in university graduates receiving considerably less exposure to the clinical environment than previously delivered. Thus, in our opinion, anecdotally HE graduates do not consolidate their practical and clinical skills as completely as in the post-employment model. Certainly the feedback from HE students in this survey supports the desire for greater practical/clinical training including clinical placements. Nevertheless, after HE graduates undertake graduate courses with the relevant EMS provider, usually of 12 months duration, the end product is a well- rounded graduate paramedic integrating both sets of ideologies. The disparity in understanding of work readiness is not only confined to the key stake-holders, the EMS providers and the higher education system, but is also endemic within the individual ambulance organisations. HE places great emphasis on developing graduates as critical thinkers, to question beyond the expected, to challenge and forge beyond the conventional. It is no surprise then that conflict arises when graduate paramedics enter a work environment that is steeped in clinical practice guidelines and specific work instructions. In addition, a question arises as to when work readiness should be measured. Graduate capabilities are a key component of benchmarking in $\mathrm{HE}$ and for most HE courses, graduate capabilities are considered at the end of the academic course. However it has become common practice for university courses that are inclusive of health sciences to measure preparedness to begin formal clinical practicum components of courses (that form the major clinical training within a course) once the student has completed a prescribed component of the course. Similarly in some states, paramedic students undertake such a practicum program inservice, that is, their course by design incorporates a period of employment with an EMS provider allowing consolidation of clinical practical skills, development of work culture, and a comprehensive understanding of the work environment. The students' preparedness to undertake the practicum program in-service may be assessed prior to beginning this practicum.

One of the fundamental issues to consider is how to best design paramedic curricula in order that graduates are indeed as work-ready as they can be, the term 'work ready' used here to denote preparedness for a life-time working within a field that is likely to change significantly over the lifespan of the graduate. In an uncertain world where climate change has begun to impact in 
unexpected and devastating ways on health of communities in Australia and internationally, and where global migration patterns are likely to change substantially as a consequence, the healthcare needs of Australia (and indeed elsewhere) ten to twenty years down the track may be very different to those of today. Wagner argues that survival in the 21 st century requires a different set of capabilities or generic skills, which include the ability to network, think critically, work in teams and communicate (amongst others).(23) These skills are not necessarily new, but newly important.(24) This suggests that the emphasis needs to change from a focus on disciplineknowledge that characterises many HE courses to a more explicit concentration on and development of such generic skills. As discussed previously, the scope of paramedic practice has already changed considerably. $(1,25,26)$ With healthcare staff shortages in rural and remote areas of Australia, the expansion of the paramedic role into primary healthcare provision and the strengthening of community healthcare collaborations in rural and remote settings is already being explored.(25)

Both models of paramedic education, the postemployment model and the pre-employment $\mathrm{HE}$ model, have strengths and weaknesses. A threeyear Bachelor course does not provide as much practical training as the post-employment model. This could be seen as significant disadvantage of the pre-employment (HE) model in comparison to the post-employment model. Indeed the responses to Part 2 of our survey indicate the importance of clinical practice and placements to students in preparing them to enter the workforce as paramedics. However, an advantage of the HE approach is the underpinning pedagogy that nurtures the development of critical appraisal, research and problem-solving skills, and skills to be life-long learners, producing graduates who can adapt to a rapidly changing world in which the scope of the paramedic may look very different to what it is today. In practice graduates of threeyear university paramedic courses complete 12 months of additional training with the relevant state ambulance authority, and in this way, gain additional experience on the job. These graduate courses are not dissimilar to their nursing counterparts who undertake a graduate program once having completed their degree. In Australia, we suggest a more effective means of educating paramedics may entail collaboration between the HE institution and the respective state authority ambulance service to design a four year degree course that combines the best attributes of the post-employment model (sufficient practical training equipping students with sound clinical and practical knowledge and skills) with the HE pedagogical approach. This may help address what a Monash University study of paramedic undergraduates found: a gap between theory and practice and lack of engagement for many students in patient management during clinical placements.(27) In the collaborative development of a four-year course, some of the deficiencies identified by Williams and colleagues including duplication of education and training that new graduates receive, 'a lack of consistency about educational ideology between university providers and industry stakeholders', and 'a mismatch and divergence between professional training and onthe-job paramedic roles' could be addressed.( 28) This may include development of paramedic course learning outcomes or graduate attributes that are appropriate for HE courses; Williams and colleagues' study may provide a useful starting point.(28) Future curricula will need to heed the growing need for education of paramedics in areas including mental health, delivery of culturally appropriate healthcare, dealing with emergency situations involving special needs children, contending with death and dying.(5) There is also a need for greater emphasis on development of 'soft skills' including interpersonal skills, identified as an issue by Lazarsfeld-Jensen as important for road readiness.(29)

\section{CONCLUSION}

This is the first study to investigate paramedic final year students' perceptions of preparedness for the workforce, in Australia. Despite the low response rate to the survey of final year students of a HE paramedic course, responses to the longanswer questions provide paramedic educators with some clear ideas about what final year students value in terms of preparing them for practice. Clinical practice opportunities are valued however, a common theme emerging was a desire for more and varied clinical placements. A common understanding of what 'work readiness' entails, between employers and educators, is needed. As Australian paramedic education moves from a post-employment training model to a pre-employment model, what needs to be further examined is how courses will address the development of clinical and practical skills of students and meet the requirements of ambulance service employers. Collegiate dialogue between employers, educators and students will assist in addressing this.

What is missing in this discussion is a clear idea of the perceptions of paramedic employers on workplace readiness of paramedic graduates from Australian paramedic education programs, including what skills and knowledge are required by employers from a graduate paramedic. Such a study has recently been completed. This 
information may help inform educators and improve the work readiness capabilities of graduates of Australia paramedic education programs.

\section{CONFLICT OF INTEREST}

The authors state they have no conflict of interest.

\section{REFERENCES}

1. Willis E, Pointon T, O'Meara P, McCarthy C, Lazarsfeld Jensen A. Paramedic education: developing depth through networks and evidence-based research. ALTC Final Report 2009. Available at URL:

http://www.acap.org.au/index.php [accessed 2 May 2012]

2. Productivity Commission. Australia's Health Workforce, Research Report, Canberra, 2005. Available at URL: http://www.www.pc.gov.au/_data/assets/pdf_fi le/0003/9480/healthworkforce.pdf [accessed 8 July 2013]

3. Dawson D. Evaluation of the Bachelor of Health Science (Paramedic) degree program at Victoria University. Masters Thesis, University of Melbourne, 2008.

4. Council of Ambulance Authorities. Discussion paper. When something goes seriously wrong. Council of Ambulance Authorities, Melbourne, 2012.

5. Hou X-Y, Rego J, Service M. Review article: Paramedic education opportunities and challenges in Australia. Emergency Medicine Australasia 2013; 25: 114-119.

6. Williams B, Onsman A, Brown T. From stretcher bearer to paramedic: the Australian paramedics' move towards professionalism. J Emergency Primary Health Care 2009; 7(4): Article 990346.

7. Waxman A, Williams B. Paramedic preemployment education and the concerns for our future: what are our expectations? J Emergency Primary Health Care 2006; 4(4).

8. Hettich, P. Transition processes from college to career. Paper presented at the Annual Conference of the American Psychological Association (108, August 4-8, 2000, Washington, DC). Available at URL: http://eric.ed.gov. [accessed 14 Jan 2011]

9. Bojanic, K, Schears, GJ, Schroeder, DR, Jenkins, SM, Warner, DO, \& Sprung, J. Survey of self-assessed preparedness for clinical practice in one Croatian medical school. BMC Research Notes 2009, 2:152.

10. Blumenthal, D, Gokhale, M, Campbell, EG, Weissman, JS. Preparedness for clinical practice: reports of graduating residents at academic health centres. JAMA 2001, 286; 9: 1027-1034.

11. Dean, SJ, Barratt, AL, Hendry, GD, Lyon, PMA. Preparedness for hospital practice among graduates of a problem-based, graduate-entry medical program. MJA 2003; 178: 4: 163-166.

12. Arena G, Kruger E, Holley D, Millar S, Tennant M. Western Australian dental graduates' perception of preparedness to practice: a five year follow-up. J Dental Educ 2007; 71(9): 1217-1222.

13. Goldsworthy, A, Pickhaver, A, Young, W. They seem different somehow. Adelaide, South Australian College of Advanced Education, 1984.

14. Hart, AM, Macnee CL. How well are nurse practitioners prepared for practice: Results of a 2004 questionnaire study. J Am Acad Nurse Practitioners 2007; 19(1): 35-42.

15. Moore, A, O’Brien, K, Canaway, R. Chinese medicine students' preparedness for clinical practice: an Australian survey. J Altern Complem Med 2010; 16:7: 733-743.

16. Jones, M, Mclntyre, J, Naylor, S. Are physiotherapy students adequately prepared to successfully gain employment? Physio 2010; 96: 169-175.

17. Hodgetts, S, Hollis, V, Triska, A, Dennis, S, Madill, H, \& Taylor, E. Occupational therapy students' and graduates' satisfaction with professional education and preparedness for practice. Can J Occup Ther 2007; 74: 3: 148160.

18. Hill J, Rolfe I, Pearson S, Heathcote A. Do junior doctors feel they are prepared for hospital practice? A study of graduates from traditional and non-traditional medical schools. Medical Education 1998; 32: 19-24.

19. Cortina, J. What is coefficient alpha? An examination of theory and applications. J App Psychol 1993; 78: 1: 98-104.

20. Council of Ambulance Authorities Inc. Submission to the National Health and Hospitals Reform Commission (May 2008). Available at URL:

http://www.health.gov.au/internet/nhhrc/publis hing.nsf/Content/070caai/\$FILE/Submissions $\% 20070 \% 20$ $\% 20$ The $\% 20$ Council\%20of\%20Ambulance $\% 2$ OAuthorities\%20Inc\%20Submission.pdf [accessed 15 July 2013]

21. Barrie, S, Hughes C, Smith, C. The national graduate attributes project: integration and assessment of graduate attributes in curriculum. Australian Learning and Teaching Council 2009. Available at URL:http://www.itl.usyd.edu.au/projects/nation algap/resources/resources.htm 
22. Bosanquet, A. Brave New Worlds,

Capabilities and the Graduates of Tomorrow. Cultural Studies Review 2011;17(2): 100-114.

23. Wagner T. The Global Achievement Gap: Why Even Our Best Schools Don't Teach the New Survival Skills Our Children Need- And What We Can Do About It. New York: Basic Books, 2008.

24. Silva E. Measuring skills for 21 st century learning. Phi Delta Kappan 2009; 90(9): 630634. In Larson LC, Northern Miller T. 21st century skills: prepare students for the future. Kappa Delta Pi Record 2011: 121-123.

25. Council of Ambulance Authorities. Discussion Paper for the Review of the Report on Government Services. Council of Ambulance Authorities Inc., 2009. Available at URL: http://caa.net.au/images/stories/CAA_submiss ion_Review_RoGS_July_2009.pdf [accessed 4 March 2012]

26. Edwards, D. Paramedic preceptor: work readiness in graduate paramedics. The Clinical Teacher 2011, 8: 79-82.

27. Michau R, Roberts S, Williams B, Boyle M. An investigation of theory-practice gap in undergraduate paramedic education. BMC Med Educ 2009; 9: 23.

28. Williams B, Onsman A, Brown T. Australian paramedic graduate attributes: a pilot study using exploratory factor analysis. Emerg Med J 2010; 27: 794-799.

29. Lazarsfeld-Jensen A (2010). Starting young: the challenge of developing graduates' road readiness. J Paramedic Practice 2010; 2(8): 368-372.

30. O'Brien, K, Hartley, P, Dawson, D, Quick, J, and Moore, A. Work readiness in paramedic graduates - what are employers looking for? (In preparation). 


\section{APPENDIX 1:}

\section{Survey of Work Readiness in Final Year Australian University Students- Parmedics}

\section{Part 1}

Please choose one response from the six (6) possible responses (tick the relevant response) for the following statement as it relates to each topic below:

At this point in time, I feel prepared to Possible responses:

$\mathrm{O}$ very inadequately $\mathrm{O}$ inadequately $\mathrm{O}$ somewhat inadequately $\mathrm{O}$ somewhat adequately $\mathrm{O}$ adequately $\mathrm{O}$ very adequately

1. recall my knowledge of anatomy

2. perform basic life support techniques

3. communicate with patients from different cultural backgrounds

4. load and unload a stretcher from the back of an ambulance

5. conduct an accurate, concise and clear handover

6. manage my time

7. continually evaluate my own performance

8. manage a high acuity patient at a scene

9. take a history from a patient

10. formulate a diagnosis

11. cope with the stress of my work

12. invest time in developing my skills

13. communicate with other emergency service workers (i.e. police, firefighters, SES)

14. balance my work and personal life

15. work collaboratively with my paramedic collegues

16. assemble the oxygen equipment inclusive of changing the oxygen cylinders

17. communicate with elderly patients

18. apply my knowledge of pathophysiology

19. undertake a daily check of the MRX monitor/ defibrillator

20. complete incident reports as required

21. administer a drug (i.e. intramuscularly, intravenously, intranasally)

22. perform chest decompression

23. drive the ambulance safely in emergency situations

24. use my knowledge of pharmacology/drug properties

25. keep up to date with technology

26. communicate with other health care professionals

27. apply wound dressing when neccessary

28 . readily access equipment in the ambulance vehicle and restock properly

29. use my knowledge of microbiology

30. undertake an assessment of a patient

31. understand my legal responsibilities to patients

32. use de-escalation strategies in dealing with agitated patients

33. remain calm in difficult situations

34. communicate effectively with bystanders

35. participate in professional association activities (i.e. with the Australian College of Ambulance Professionals)

36. discuss stressful experiences with colleagues

37. act in an ethical way towards colleagues

38. communicate with relatives and bystanders in the event of a patient becoming deceased or cessation of resuscitation

39. perform spinal packaging (i.e. use a cervical collar, spine board)

40. complete an accurate patient care record using the VACIS system

41. perform fluid resuscitation in accordance with the approved CPG

42. communicate with patients from low socioeconomic groups

43. use ambulance communication systems

44. follow Clinical Practice Guidelines

45. communicate effectively with suicidal patients 
46. carry out a vehicle check

47. achieve musculoskeletal immobilisation

48. prime a giving set

49. apply my knowledge of human physiology

50. use an MRX cardiac monitor/ defibrillator for recording ECG (electrocardiograph)

51. be culturally sensitive in my interactions with patients

52. understand my legal responsibilities to peers

53. read and interpret ECG traces

54. engage in individual patient health education

55. effectively manage the impact of shiftwork on my sleep and health

56. maintain my clinical skills

57. act in an ethical way towards patients

58. be actively involved in the clinical guidelines review process (i.e. with Ambulance Victoria)

59. actively participate in formal debriefing

60. communicate effectively with mentally ill patients

61. apply a knowledge of organisational policies

62. communicate with patients under the influence of drugs and alcohol

63. actively participate in the development of paramedics as a profession

64. access and engage in peer support/ VACU

\section{PART 2 Extended Answer Questions}

\begin{tabular}{|l|l|l|}
\hline 1. & $\begin{array}{l}\text { Are you currently employed as a paramedic? } \\
\text { Circle your answer. Yes No }\end{array}$ & \\
\hline $\begin{array}{l}\text { If you are employed as a paramedic, for how long? } \\
\text { weeks OR months }\end{array}$ & \\
\hline $\begin{array}{l}\text { If you are employed as a paramedic, where are you employed? } \\
\text { Postcode: Or: Location: }\end{array}$ & \\
\hline
\end{tabular}

2. Do you consider that you were, or will be, prepared for the transition into the paramedic workforce at the end of your course?

3. In terms of preparing you for work as a paramedic, what were the best aspects of your course?

4. In terms of preparing you for work as a paramedic, what aspects of your paramedic course could be improved?

5. How useful were the ambulance service placements during your course in preparing you for entering the ambulance workforce?

Thank you for taking the time to provide this information. 